\title{
Corpo/matéria, gestos/material: para pensar uma estética dos esportes*
}

\author{
Body/raw, gestures/material: thinking an aesthetic of sports Abstract
}

Cuerpo/materia, gestos/material: para pensar una estética de los deportes

\author{
MiCHELle CARREIRÃo GONÇALVES** \\ ALEXANDRE FERNANDEZ VAZ***
}

\begin{abstract}
$\longrightarrow$
RESUMO

Ao se pensar em uma estética dos esportes a partir da análise de material oriundo de pesquisa empírica realizada com uma equipe de rúgbi feminino sediada na cidade de Florianópolis (SC), trabalhou-se com a perspectiva de que o cotidiano de treinamento e o momento de jogo materializado nas disputas são tempos singulares de construção do que se denomina aqui obra esportiva. Esta, tomada como artefato estético em analogia à obra de arte, parece se aproximar desta no que concerne a seus elementos constituintes, como matéria, material e forma. Volta-se o olhar especialmente para os dois primeiros, encontrando, por um lado, o corpo como matéria, materialidade que permite o modelamento e a modificação; e, por outro, os gestos técnicos, o vocabulário específico de cada modalidade, configurando-se como o material da obra esportiva.
\end{abstract}

Palavras-chave: Esporte. Estética. Educação do corpo. Rúgbi. Arte.

\begin{abstract}
This paper proposes the concept work of sport to express an aesthetic of sports. For such it works out material from an empirical research with a female rugby team based in Florianopolis, Brazil. The everyday training as well as the play moment materialized in the contest are special times of construction of the work of sport. The work of sport, taken as aesthetic artifact in analogy to the work of art, seems to approach regarding to its constituent elements, as raw, material and form. We turn our attention especially to the first two, finding, on the one hand, the body as raw, materiality that allows the modeling and modification, and secondly, the technical gestures, the specific vocabulary of each sport, configuring itself as the material of the work of sport.
\end{abstract}

Keywords: Sport. Aesthetic. Education of body. Rugby. Art.

\section{RESUMEN}

El artículo propone el concepto de obra deportiva para expresar una estética de los deportes. Para tanto toma en cuenta materiales de una investigación empírica sobre un equipo de rugby femenino en la ciudad de Florianópolis, Brasil. El entrenamiento cotidiano, así como el momento de juego que se materializa en las competiciones, son tiempos singulares en la construcción de la obra deportiva. En analogía a la obra de arte, al cual parece aproximarse en sus elementos constituyentes, la obra deportiva es tomada como artefacto estético. Volvemos nuestra mirada en especial para los dos primeros elementos, cuando encontramos, por un lado, el cuerpo como materia, materialidad que permite modelaje y transformación, y, por otro, los gestos técnicos, el vocabulario específico de cada modalidad deportiva, que se configura como material de la obra deportiva.

Palabras clave: Deporte. Estética. Educación del cuerpo. Rugby. Arte.

\footnotetext{
* O presente trabalho é resultado parcial do Programa de Pesquisas Teoria Crítica, Racionalidades e Educação (IV) e contou com apoio financeiro do CNPq nas seguintes modalidades: bolsa de doutorado, bolsa de doutorado sanduíche, bolsa de pesquisa e apoio à pesquisa.

** Doutora em Educação pela Universidade Federal de Santa Catarina; Professora da Universidade Federal do Rio de Janeiro; Membro do Núcleo de Estudos e Pesquisas Educação e Sociedade Contemporânea (CNPq/UFSC) e do Laboratório de Pesquisas em Educação do Corpo (CNPq/UFRJ). E-mail: <michelle_carreirao@yahoo.com.br>.

***Doutor em Ciências Humanas pela Leibniz Universität Hannover; Professor da Universidade Federal de Santa Catarina; Coordenador do Núcleo de Estudos e Pesquisas Educação e Sociedade Contemporânea (CNPq/UFSC); Pesquisador CNPq. E-mail: <alexfvaz@uol.com.br>.
} 


\section{INTRODUÇÃO}

O esporte parece ser uma das invenções modernas mais bem-sucedidas. Se, por um lado, cumpre importante papel social como atividade regulada que permite, momentaneamente, usufruir do prazer gerado pela libertação de tensão (ELIAS; DUNNING, 1992); por outro, inunda o cotidiano, estendendo-se para as diversas esferas sociais, e produz uma sociedade esportivizada (VAZ, 2004a), na medida em que valoriza o desempenho, a representação, a técnica e a dor.

Nesse sentido, pode-se dizer que o esporte seria a expressão da dialética do progresso (CLAUSSEN, 2006), pois neste "a liberdade e a dominação entrelaçamse no jogo e somente aquele que se submete à soberania de uma ordem no jogo pode sair do campo como vencedor" (p. 588-9). Em outras palavras, o esporte traz consigo o fascínio pelo extremado controle do corpo que possibilita a produção de momentos emocionantes, belos, inimagináveis -, na medida em que esse domínio se coloca como instância necessária para a apreensão técnica e, consequentemente, para sua realização.

Enquanto evento, o esporte mobiliza sentimentos e paixões, o que leva a sua admiração por distintos motivos: seja pelos corpos esculturais que os atletas desfilam em quadras, piscinas, campos e pistas de corrida; pela beleza dos gestos técnicos executados à beira da perfeição; seja pelas jogadas ensaiadas nos treinamentos e que, como coreografias, são realizadas na competição; seja ainda pela possibilidade de presenciar algo completamente novo, imprevisto, que, muitas vezes, não faz do movimento o mais eficiente, mas, sim, o mais belo.

Levando isso em conta, as relações entre estética e esporte ganham força como tema, em especial se o fenômeno esportivo for pensado como aquele que proporciona elevado prazer e beleza no contemporâneo, revelando "uma constituição altamente estética" (WELSCH, 2001, p. 142). O que se evidencia, tanto no que diz respeito à construção de corpos belos e, por muitos, admirados quanto à produção do momento inesperado e incerto que compõe o jogo, à fascinação pela epifania, à "aparição súbita e transitória de algo que, ao menos durante o tempo de sua aparição, tenha substância e forma simultaneamente" (GUMBRECHT, 2001, p. 4).

Se a conexão entre beleza e esporte tem sido destacada desde o século XIX, como prática e espetáculo (GONÇALVES; VAZ, 2012), é no século XX que a questão ganha desenvolvimento mais expressivo tanto no que concerne aos aparatos tecnológicos de exposição das competições esportivas (as medias) quanto no âmbito das análises teóricas sobre o tema.

Exemplar e pioneira nesse cenário é a obra Homo ludens, do historiador holandês Johan Huizinga, que, publicada em 1938, apresenta o jogo como elemento fundante da cultura. Segundo aquele livro, há a presença de características lúdicas na cultura, na medida em que "surge sob a forma de jogo, [em] que ela é, desde seus primeiros passos, como que jogada" (HUIZINGA, 2007, p. 53). Theodor W. Adorno, em sua Teoria estética, adverte, no entanto, que Huizinga, ao conferir tanta centralidade à categoria de jogo (Spiel), deste subtrai as especificidades de seu distanciamento da "práxis da autoconservação" (ADORNO, 1997a, p. 471). Apesar de Huizinga não tratar do esporte, não se pode esquecer que sobrevive neste um elemento de jogo (não é à toa que se usa o verbo jogar ao se referir à ação de praticar esportes), no qual se criam mundos de entretenimento em que liberdade, afastamento da vida corrente, isolamento e limitação a tempos e espaços singulares, bem como criação de ordem (HUIZINGA, 2007), configuram a prática.

Assim, questionar sobre possibilidades de expressão estética no esporte é pensar nos momentos de criação, liberdade e ludicidade preservados na prática, além ou aquém de seu princípio competitivo. Vencer é importante, mas até que ponto a produção de forma não ganha lugar de destaque entre os atletas ou praticantes eventuais, durante uma competição? Quantas vezes depara-se com belas jogadas, mesmo não sendo sempre estas as mais eficientes? Seguindo por esse caminho, alguns autores têm se dedicado contemporaneamente ao tema, mostrando a inegável presença de um momento de fruição e gozo estéticos no contato com o esporte, entre eles, Wolfgang Welsch, Gunter Gebauer, Christoph Wulf, Hans Ulrich Gumbrecht e José Miguel Wisnik ${ }^{1}$.

Vale ressaltar que esses autores miram o fenômeno a partir de um ponto de vista específico, a saber: o da recepção. $\mathrm{O}$ foco está na experiência daquele que assiste ao esporte, no aficionado que vai aos estádios e ginásios, e que também a tudo acompanha pela tela da televisão - e pode-se agregar ainda, pela dos dispositivos móveis. Mesmo utilizando alguns relatos de atletas, a perspectiva desses autores é, predominantemente, de fora, é o olhar de quem consome e não de quem produz esporte (inclusive falam, muitas vezes, do seu lugar de fãs de esporte e, a partir deste, elaboram suas considerações, como no caso de Gumbrecht).

Neste texto, entretanto, a proposta é analisar a possibilidade de uma estética dos esportes a partir da ideia de construção do que se denomina aqui obra

\footnotetext{
${ }^{1}$ Destacam-se as seguintes obras que tomam o esporte como artefato estético: GEBAUER, G; C., WULF. Mimese na cultura: agir social, rituais e jogos, produções estéticas, 2004; WELSCH, W. Esporte - visto esteticamente, e mesmo como arte?, 2001; GUMBRECHT, H.U. Elogio da beleza atlética, 2007; WISNIK, J.M. Veneno remédio: o futebol e o Brasil, 2008.
} 
esportiva, que, segundo a perspectiva apresentada, é forjada tanto pelo cotidiano de treinamento como pelo momento de jogo materializado nas disputas. Assim sendo, lida-se com dados produzidos por meio de uma pesquisa empírica constituída de incursões etnográficas realizadas com uma equipe feminina de rúgbi sediada na cidade de Florianópolis/SC. O trabalho de campo ocorreu entre os anos de 2011 e 2013, gerando um conjunto de observações sistemáticas do cotidiano de treinamento e de competições da referida equipe (devidamente registradas em caderno de campo), bem como da seletiva da Confederação Brasileira de Rugby (CBRu), realizada em 2011, na cidade de São Paulo, em que algumas jogadoras do clube pesquisado participaram. Somam-se a isso quatro entrevistas semiestruturadas com as integrantes daquele time escolhidas por seu destaque na equipe, além de sua participação no selecionado nacional.

Procurando compreender a construção da obra esportiva, considerou-se o esporte como artefato estético em analogia à obra de arte, especialmente no que concerne a seus elementos constituintes, como matéria, material e forma. Importante destacar que o entendimento de tais características encontradas, primordialmente, na arte, inspira-se na estética adorniana. Aqui, entretanto, em se tratando do esporte e não da arte, analisam-se as fontes empíricas a partir das categorias matéria e material, ficando a forma reservada para outro momento. No primeiro caso, encontra-se o corpo, a materialidade que permite o modelamento e a modificação; já no segundo, encontram-se os gestos técnicos, o vocabulário específico de cada modalidade. A seguir, observa-se como essas questões se articulam.

\section{CORPO E MATÉRIA}

Como ocorre em qualquer prática esportiva, o corpo é alvo de constante cuidado, apreço, dedicação, o que faz todo o sentido se for considerado que é por meio deste que o esporte se realiza. Assim, é possível pensá-lo como matéria da obra esportiva, aquele elemento tomado da realidade em sua imediatidade que, a partir da objetivação do espírito, resulta no material da obra. Para melhor compreender essa relação, inspiramo-nos na estética adorniana, na dialética entre matéria e material artístico.

Nesta, a matéria é considerada como estofo (Stoff), materialidade, matéria-prima bruta a ser transformada pelo engenho humano. O material deriva, por sua vez, dessa transformação, sendo, por isso, formado, já que não é algo natural, "mas histórico e sempre histórico" (ADORNO, 1997a, p. 223), pois traz em si a herança da tradição, mesmo quando a critica:
Eles [os materiais] não são menos dependentes das transformações técnicas do que elas dos materiais, que ela por sua vez reelabora. Evidentemente, e de forma muito semelhante ao compositor que opera com o material tonal, é da tradição que se dá a recepção. Ele utiliza, no entanto, para critica-lo, um [material] autônomo, purificado de conceitos como consonância e dissonância, tríade, diatônica, já que é na negação que o negado está contido (ADORNO, 1997a, p. 223).

Nesta passagem é possível ver o caráter dialético da análise adorniana sobre a obra de arte, o movimento da Aufhebung (suprassunção) apresentando-se também na realização artística, na medida em que as técnicas e materiais se renovam, excluindo e guardando, concomitantemente, as determinações daqueles que lhes foram anteriores, gerando uma forma nova.

Partindo desse princípio, ao se considerar o esporte como obra estética, analisa-se o corpo como matéria na medida em que é tomado como pura natureza, como organismo, pelo treinamento esportivo. É por meio de uma visão instrumental do corpo que o treinamento atua sobre este, aprimorando sua capacidade morfofisiológica, bem como seu desempenho técnico. Esse olhar sobre o corpo como materialidade manipulável é a base para o treinamento, que tem por objetivo a progressiva adaptação daquele a determinados estímulos, com vistas ao melhor rendimento, por meio da superação de um estado fisiológico (mas também técnico) anterior.

Partindo-se desse processo de manipulação racional (chamado treinamento) da matéria bruta (do corpo, ou do organismo), chega-se não apenas ao melhor condicionamento físico, mas também às condições para a incorporação dos gestos técnicos específicos de cada modalidade. A condição física aprimorada é requisito para a incorporação técnica dos movimentos que se configuram como o ponto de partida da produção de forma da obra esportiva.

Assim, se o corpo constitui-se em matéria da obra esportiva, imprescindível que seja, sistematicamente, objeto de cuidado, mas também de destruição, na medida em que a matéria precisa ser violentada para tornarse material. Analogamente ao que ocorre no trabalho artístico, "que sempre seleciona, extirpa, renuncia: não há forma sem Refus" " (ADORNO, 1997a, p. 217), no esporte faz-se também presente o momento de violência sobre o corpo, de renúncia de seus impulsos e domínio de suas paixões. Somente por meio de tal processo é que se podem alcançar as exigências de desempenho presentes na prática.

No caso pesquisado, o rúgbi, isso não é diferente. Os resultados das incursões etnográficas deixam ver

\footnotetext{
2 Do francês, "Recusa".
} 
questões ligadas ao corpo e a sua manipulação, elemento corriqueiro no cotidiano das jogadoras estudadas, bem como da maioria dos atletas. Destaca-se um elemento que parece exemplar no que concerne ao trato do corpo tomado como matéria a ser transformada para produção da obra esportiva, a saber: a preparação física.

Ao longo do trabalho de campo, deparou-se com uma elevada exigência no que diz respeito à preparação física das jogadoras de rúgbi, em especial daquelas que compõem o quadro do selecionado brasileiro, as informantes desta pesquisa. Tal exigência se justificaria, segundo as depoentes, pelo fato de ser o rúgbi, no formato sevens $^{3}$, um jogo muito veloz, consequência de seu curto período de disputa (14 minutos, divididos em dois tempos de sete) e do reduzido número de integrantes por equipe (sete), o que torna necessário um preparo físico especial para suportar o ritmo intenso. A seguir, uma passagem do caderno de campo que ilustra a questão:

\begin{abstract}
"P. [técnico] comenta que os reinícios de jogo precisam ser mais rápidos. Ele diz que o jogo oficial tem 14 minutos e que é preciso utilizar bem todo o tempo. P. [novata] diz, sobre o tempo de jogo: 'Só isso?'. J. [veterana] ri e P. [técnico] fala: 'Depois de três minutos vou te perguntar se está cansada'."4
\end{abstract}

Esse recorte aponta para a necessidade de preparação dos corpos das jogadoras que precisam suportar o desgaste derivado da corrida intermitente e em ritmos variados durante o jogo, além daquele resultante do contato físico constante das concorrentes nas disputas de bola. É preciso ter força, velocidade e resistência para tacklear, fazer um ruck, um maul, um scrum, cobrar um lineout ${ }^{5}$, e levantar-se rapidamente do chão para receber a bola, aguardando o momento de ir novamente ao solo ao derrubar ou ser derrubada. Exemplar nesse sentido é o comentário de uma

\footnotetext{
3 O formato tradicional do jogo de rúgbi é o 15-a-side (ou XV), ou seja, com 15 jogadores por equipe, disputado em dois tempos de 40 minutos. Mas há ainda o 7-a-side - aqui denominado simplesmente de sevens, nomenclatura advinda do discurso nativo - que caracteriza-se por sete jogadores por time, tendo uma duração de dois tempos de sete minutos. No Brasil, as mulheres disputam apenas a modalidade sevens.

4 Relato 8,03/08/2011.

5 Tacklear é o gesto de defesa caracterizado pela derrubada do adversário que está de posse da bola. Ruck, maul, scrum e lineout são formações de disputa de bola. No caso do primeiro, ocorre quando um jogador de posse da pelota vai ao chão e seus companheiros de equipe procuram protegê-la, mantendo-a em seu campo de jogo; por outro lado, a equipe adversária tenta deslocar tais jogadores com o objetivo de tomar a bola para si. No maul, a disputa se dá em pé, ou seja, quando o jogador que está com a bola tem a passagem obstruída por seu oponente, mas sem ir ao solo; nesse caso, constrói-se uma formação móvel, em que um grupo de jogadores de ambas as equipes vão se empurrando, procurando conquistar território e a pelota. O scrum é uma formação de tipo ordenada realizada com oito (no caso do jogo de 15) ou três jogadores (se for no formato de sete) para disputar a posse de bola depois de uma falta leve. Já o lineout é o lateral que deve ser cobrado com a delimitação de duas colunas paralelas (uma de cada time); a bola lançada é disputada, podendo ocorrer o famoso "elevador", que consiste no levantamento de um dos jogadores da coluna para facilitar o contato com a bola.
}

jogadora sobre um exercício que se observou do treino da equipe e que, segundo ela, remete à dinâmica do jogo. Em suas palavras: "Você tá morta, derrubando, derrubando e, de repente, você tá com a bola e tem que atacar. Tá morta, mas tem que correr"6.

Por isso é preciso suportar firmemente as agruras do treinamento físico, pois as adversidades, segundo o discurso nativo, fazem parte do rúgbi. Essa questão, somada ao caráter amador da modalidade, que valoriza o sacrifício em nome do grupo, resulta no discurso no qual a superação das dores, do cansaço, das lesões e das dificuldades técnicas aparece como necessária à prática. Encontra-se a mesma lógica em pesquisas realizadas com atletistas, bailarinas e caratecas: a dor e o sofrimento, interpretados como elementos que fazem parte do jogo que leva à concretização do projeto de performance perseguido por todos. O mesmo acontece no rúgbi, em que também se deve viver no limite das potencialidades do corpo. Assim como os atletistas, lutadores e bailarinas, as jogadoras de rúgbi "sofrem, mas acreditam ser superiores e fortalecid[a]s após cada superação" (GONÇALVES; TURELLI; VAZ, 2012, p. 147).

Para se alcançar a tão almejada performance, são necessários muitos investimentos sobre o corpo. Assim, além das sessões de treinamento do clube (que à época das incursões etnográficas ocorriam às segundas, quartas e sábados, com duração de aproximadamente duas horas a cada vez), era preciso também oferecer atenção especial à preparação física. Naquele momento (ano de 2011), não havia um trabalho específico durante o treino e, por isso, as jogadoras se organizavam para fazer, por conta própria ${ }^{7}$, os exercícios correspondentes em outros horários.

Importante dizer que, em 2013, retornou-se a campo, depois de um ano, e encontrou-se já uma nova configuração. A mudança de técnico alterara a dinâmica de treinamento do grupo. Uma das novidades era o trabalho de preparação física que compunha uma parte das sessões de treinamento do clube, nos 30 minutos iniciais dos encontros. Somado a isso, as jogadoras se organizaram e iniciaram um treino de musculação funcional ${ }^{8} \mathrm{em}$ uma academia que lhes cobrava preço promocional porque uma das integrantes da equipe lá trabalhava. Por fim, agregouse um preparador físico (também jogador do clube)

\footnotetext{
6 Relato 3, 04/07/2011.

7 Vale ressalvar que havia uma espécie de autogerência no que concerne aos treinos físicos naquele momento, pois as próprias jogadoras organizavam as atividades, independentemente das orientações do técnico. Tal organização tinha por base, por um lado, as experiências pregressas de algumas delas com outros esportes, como o atletismo, por exemplo, o que agregava certo conhecimento de preparação física; mas também, por outro, o fato de algumas jogadoras serem formadas em Educação Física, inclusive trabalhando na área de musculação.

8 O chamado treinamento funcional objetiva melhorar a condição física para a execução de determinada tarefa. Para tal, trabalha com movimentos básicos, como agachar, empurrar, girar, saltar e correr.
} 
para auxiliar o grupo. Suas instruções dividiam-se entre o treinamento funcional e a preparação física em campo.

Já no caso das jogadoras da seleção, o treino físico era ainda mais intenso, constituindo-se em exigência para se manterem no grupo de alto rendimento. Conforme relataram as informantes, as planilhas de treinamento que recebiam de São Paulo, diretamente da $\mathrm{CBRu}$, enfocavam a preparação física, ficando a parte técnica sob responsabilidade dos clubes. Segundo ficou constatado nas entrevistas, suas rotinas de treinamento, em especial aquelas voltadas à preparação física, eram muito volumosas. Costumavam ter de duas a três sessões de treino por dia, seis vezes por semana (descansando apenas aos domingos), que precisavam ser conciliadas com as outras atividades diárias, como trabalho e estudo.

Tal rotina exige um alto grau de dedicação das jogadoras ao rúgbi, notadamente daquelas atuantes na seleção, pois o dia gira em torno do esporte, em meio aos treinos de preparação física, técnico-táticos, cuidados com sono, alimentação, suplementação etc. É preciso manter uma postura vigilante e de controle que parte, num primeiro momento, do staff técnico (preparador físico e treinador, por exemplo), mas que exige uma gradual internalização por parte das jogadoras, que passam à autogerência. São responsáveis por realizar os treinos por conta própria, sem nada poder negligenciar, sob pena de perder a vaga na equipe.

Essa questão é exemplar no que se refere à necessidade, por parte das jogadoras, de uma incorporação das normas, regras, proibições e exigências do treinamento esportivo, por meio daquela "dedicação quase monástica" de que fala Sabino (2000) em relação à prática da musculação e à consequente aquisição da forma física desejada. Para tanto, deve-se seguir, religiosamente, as prescrições relacionadas à alimentação, ao esforço físico repetitivo, ao tempo de dedicação ao esporte, enfim, aceitar as regras do jogo do treinamento. Mas tal submissão é também um investimento para se concretizar o projeto que cada uma alimenta: ser jogadora de rúgbi. Para isso, é preciso administrar seu maior bem: o corpo. Essa administração passa não somente pelas técnicas de potencialização (musculação, corridas, dieta, treinos com bola etc.), mas inclui ainda aquelas de proteção e preservação corporal, com intuito de "fazer frutificar seu capitalcorpo" (WACQUANT, 2002, p. 148). Assim como os pugilistas estudados por Wacquant, as jogadoras de rúgbi também dispõem de um conjunto de dispositivos de cuidados com o corpo, em especial para tentar amenizar os possíveis danos causados pelo excesso de estresse a ele infligido pelo próprio treinamento. O principal recurso é, sem dúvida, a fisioterapia, utilizada não apenas para o tratamento, mas também para a prevenção de lesões. Sobre isso, relata uma informante:
“[...] eu vou à fisioterapia, que eu faço mesmo quando estou sem dor. Eu faço fisioterapia preventiva porque eu já tive muitas lesões. [...] Eu quero incluir na minha rotina de treino exercícios que ajudem na prevenção de lesões." 9

Nesse cenário, o corpo se apresenta não apenas como potencial (de rendimento), mas também como um empecilho que determina a continuação ou interrupção da prática, na medida em que seus limites se impõem, na maioria das vezes, na forma de lesões. Isso mostra que há neste uma fragilidade que nem mesmo o mais controlado treinamento pode evitar, já que esse processo cientificamente elaborado gera, concomitantemente, desempenho e debilidade, ao transformar a matéria (corpo) em material (gestos), por meio de alguma violência.

Mas a matéria é apenas um elemento (talvez o mais primevo) nessa configuração do que chamamos de obra esportiva. É preciso ainda entender o lugar do material na composição chamada esporte.

\section{GESTOS E MATERIAL}

O rúgbi tem uma dinâmica de jogo muito específica que combina passes com as mãos, chutes, derrubadas, empurrões e levantamentos, além da particularidade de só se poder passar a bola para um companheiro que esteja posicionado atrás daquele que tem a posse da pelota. A combinação dos distintos elementos faz com que o rúgbi tenha uma forma um tanto diversa dos esportes coletivos mais tradicionais na cultura brasileira, como o futebol, o voleibol, o handebol e o basquetebol, por exemplo, que, geralmente, apresentam um vocabulário de movimento mais rígido, permitindo a utilização apenas das mãos ou dos pés.

Se antes tratou-se da matéria (corpo) da obra esportiva, faz-se necessário agora olhar mais detidamente para o material: os movimentos, os gestos técnicos por meio dos quais se realiza o jogo, aquilo com que lidam os esportistas. Esses gestos são, segundo Gebauer (1995), uma elaboração simbólica das ações cotidianas, espécie de codificação (Codifizierung) da práxis social, que lembra o mundo ordinário, mas apenas em referência a este, sem corresponder literalmente à realidade. Nesse sentido, diz o autor, o esporte guarda uma relação com o trabalho do ator $\left(\right.$ Schauspieler $\left.^{10}\right)$, pois em ambos há uma representação do real materializada nos gestos.

\footnotetext{
9 Entrevistada Joana, 31 anos (dado referente ao ano de 2013, quando da realização da entrevista), jogadora de rúgbi desde 2004, ano em que também começou a atuar na seleção brasileira. No momento da pesquisa (2011 a 2013), era a capitã do selecionado nacional.

${ }^{10}$ Aqui, talvez, valha destacar a etimologia da palavra Schauspieler, que contém em si dois vocábulos: Schau e Spiel. O primeiro significa "visão" e o segundo "jogo", "interpretação" (no sentido de atuação artística) e "execução" (musical).
} 
Tais gestos constituem-se em vocabulário de cada modalidade, um sistema de signos que articula uma linguagem e que permite uma comunicação entre os cifradores (jogadores) e os decifradores (espectadores). Interação possibilitada pelo compartilhamento de um mesmo código (PASOLINI, 2005). Assim como a língua escrita e falada é composta por unidades mínimas não significantes (grafemas e fonemas) que, combinadas, geram as palavras, pode-se pensar analogamente, inspirando-se em Pasolini, no esporte. Os gestos técnicos corresponderiam, isoladamente, aos fonemas e grafemas que não têm sentido em si, mas apenas no contexto do jogo. As jogadas, que exigem uma articulação entre técnica e tática, seriam as palavras, que possibilitam a comunicação, o diálogo entre os jogadores (do mesmo time ou adversários), bem como entre eles e os espectadores. Por fim, o jogo, o evento, representaria o texto em que "a sintaxe se exprime [...] [como] um verdadeiro discurso dramático" (PASOLINI, 2005, p. 4).

No caso do rúgbi, os gestos técnicos e movimentos durante o jogo são realizados em função da bola, objeto central de disputa nessa modalidade, assim como em muitas outras. Sendo assim, não é sem sentido constatar que é a pelota elemento essencial também no treino. A realização de movimentos que envolvem o contato, a posse e o manuseio da ovalada $^{11}$ foram uma constante nas sessões de treinamento observadas, tanto para aquelas que chegavam (novatas) quanto para as que jogavam havia mais tempo (veteranas ${ }^{12}$ ). O manuseio da bola oval é uma dificuldade a ser superada para que se possam realizar bons passes e dar continuidade ao jogo que, como já destacado no formato sevens, é muito veloz e dinâmico, exigindo um trabalho ágil com a pelota. Apesar de ser também permitida a utilização de chutes, quase não se presenciou a realização de treinos voltados a estes ${ }^{13}$. A ênfase estava colocada sobre o passe (com as mãos), já que esta é a maneira mais segura ${ }^{14}$ e mais eficaz de fazer a bola circular entre as jogadoras para se chegar ao objetivo final, ao $t r y^{15}$.

\footnotetext{
${ }^{11}$ Forma carinhosa de denominar a bola de rúgbi, entre os nativos, derivada de seu formato oval.

${ }^{12}$ Os termos novata e veterana também compõem o vocabulário nativo.

${ }^{13}$ Os treinos de chute partiam, de uma forma geral, da iniciativa de algumas jogadoras específicas, que eram as chutadoras do time, e consistiam na realização de algumas repetições de chute antes ou depois do treino, mas raramente durante e quase nunca com orientação do técnico.

${ }^{14}$ Chutar uma bola de rúgbi não é algo muito simples, justamente devido ao seu formato ovalado. Além disso, quando esta toca o solo, depois do chute, tende a quicar para outra direção, já que não é redonda. Isso tudo faz do chute um recurso mais impreciso do que o passe. Vale dizer ainda que, segundo as informantes, utiliza-se pouco o chute no rúgbi feminino.

${ }^{15} \mathrm{O}$ try é a forma de obter a maior pontuação em um jogo de rúgbi (cinco pontos cada). Consiste em apoiar a bola no chão, no in-goal adversário, uma área delimitada ao final das duas extremidades do campo. Há ainda mais três maneiras de pontuar: chute de conversão (dois pontos), chute de penal (três pontos) e o droap goal (três pontos).
}

Assim como na arte, em que o artista repete um gesto, uma fala, um acorde, uma pirueta, uma nota, para poder, enfim, executá-los com perfeição, é preciso também no esporte repetir, repetir e repetir incansavelmente o gesto, como o do passe, para refiná-lo tecnicamente, memorizando-o corporalmente, até que se naturalize, automatize-se. Somente quando a técnica está perfeitamente ajustada ao corpo, incorporada, quando sua realização não exige tanto esforço e cálculo, é que se abre espaço para a criação e expressão (tanto na arte quanto no esporte), ao se explorar o vasto repertório técnico que se tem à disposição, combinando-o com criatividade e imaginação.

Essa aprendizagem, bem como seu desenvolvimento e complexificação, representa um processo de apreensão técnica. Recurso que, muitas vezes, passa por uma relação mimética entre jogadoras e técnico (tradicionalmente, o técnico é um ex-jogador ou mesmo um jogador ainda atuante), na medida em que aquelas procuram se aproximar deste no que diz respeito à execução dos gestos. Por isso tantas demonstrações por parte dele, incluindo não apenas a mera execução do movimento, mas, também, nos momentos de maior dificuldade, o auxílio do toque no corpo das jogadoras ${ }^{16}$. O que indica qual é a forma do gesto (pegando nos braços, por exemplo, e realizando, juntamente com a jogadora, o movimento correto dos membros), para que elas possam, além de ver o movimento, também senti-lo na própria pele, com o próprio corpo, como deixa ver a seguinte passagem:

\begin{abstract}
"Variam passes. P. [técnico] pede para realizarem um de costas, movimento bem mais complexo que os outros. Os erros são constantes. M. [veterana] diz que "precisa esticar os dedinhos", mas não consegue executar o passe. P. [técnico] então para o exercício e pergunta ao grupo como estão fazendo o movimento. M. [veterana] demonstra. P. [técnico] explica como fazer, mostrando para J. [veterana] (toca em seus braços e mãos para demonstrar o movimento). Faz o mesmo com V. e M. [veteranas], que também estavam com dificuldade". ${ }^{17}$
\end{abstract}

Isso revela que o esporte trabalha com um conhecimento não conceitual, que tem origem na

\footnotetext{
${ }^{16}$ Durante participação na seletiva da CBRu, no início de 2011, conversouse informalmente com o responsável técnico da modalidade, que falou sobre a dificuldade inicial de trabalhar com o rúgbi feminino, por ser uma prática tradicionalmente restrita aos homens. Uma das questões por ele levantada foi, justamente, o toque. Diferentemente do que ocorria quando treinava equipes masculinas, impôs-se uma problemática: como tocar o corpo das jogadoras para explicar e ensinar os gestos técnicos? A solução por ele encontrada, segundo relatou, foi inverter a ação: ao invés de tocar nas jogadoras, elas que tocavam nele. Aqui, vê-se, para além do interdito corporal, em que homens não podem tocar as mulheres, o papel desempenhado pelo toque na aprendizagem dos movimentos.

${ }^{17}$ Relato 5, 11/07/2011.
} 
mimese (ADORNO) e no senso prático (BOURDIEU), conforme os termos apresentados por Gebauer (1995). No que concerne à mimese, Gebauer considera o segundo movimento da capacidade mimética, que, para Adorno, está reservada à arte, bem como às brincadeiras infantis, e guarda em si o potencial reconciliador, na medida em que remete ao estado prototipicamente indiferenciado de sujeito e objeto, uno e múltiplo. Afinal, arte "é racionalidade que critica a racionalidade sem dela subtrair-se" (ADORNO, 1997a, p. 87), fabricando a imagem que remete à reconciliação com a natureza.

É preciso aqui dizer que Adorno analisa a mimese a partir de um duplo movimento. O primeiro estaria ligado à autoconservação, relacionado à capacidade de, em estágios primitivos, camuflar-se na natureza, dissolver-se e misturar-se nesta como recurso extremo de sobrevivência. Esse assemelhamento tem para o autor um sentido negativo, na medida em que representa uma renúncia do sujeito de si mesmo a partir de sua identificação com o outro, sua diluição irracional nesse outro. Disso resulta a mimese perversa ou mimetismo ${ }^{18}$. O segundo movimento, por outro lado, não se reduz à mera regressão, mas apresenta uma relação não danificada entre sujeito e objeto, uma relação não de identidade, mas, precisamente, de semelhança. Mimese aqui é representação, ação do sujeito, uma forma de conhecer a partir de uma "aproximação do outro que consiga compreendê-lo sem prendê-lo e oprimi-lo, que consiga dizê-lo sem desfigurá-lo". Que reflita uma proximidade, permitindo a manutenção da diferença e do distanciamento entre sujeito e objeto, num "conhecimento sem violência nem dominação" (GAGNEBIN, 2005, p. 101). No caso aqui analisado, o esporte, mais especificamente o rúgbi, o impulso mimético se apresenta no momento de aprendizagem dos movimentos da modalidade. Expõe-se por meio da observação dos mais experientes (especialmente do técnico, mas também de outras jogadoras, como as veteranas, por exemplo, que têm mais tempo de prática) e na consequente tentativa de a eles se assemelhar, como anteriormente assinalado.

Já no que diz respeito ao senso prático, Gebauer ressalta que há no esporte, assim como no mundo social, um conhecimento corporal que permite o agir sem reflexão. Conforme elabora Bourdieu (1999), este consiste em um conhecimento incorporado por meio de experiências acumuladas, que geram esquemas de percepção, apreciação e ação que envolvem conhecimentos práticos e possibilitam reações a determinados estímulos sem a realização de nenhum cálculo racional.

\footnotetext{
${ }^{18}$ Esta é uma noção muito importante para os estudos sobre indústria, cultura e dominação política empreendidos por Horkheimer e Adorno (1997).
}

Exemplar nesse sentido, mostra Gebauer, é a capacidade de antecipação, de prever um acontecimento e gerar prontamente uma resposta. Ainda nesse quadro, tem-se a relação do senso prático com os movimentos técnicos de cada modalidade, que são um desdobramento do conhecimento prático do corpo a partir de um conjunto codificado de gestos. No caso do rúgbi, observou-se o senso prático ligado aos movimentos com e sem bola, ambos importantes para a continuidade do jogo. Essa movimentação pode ocorrer durante a defesa, mas também no ataque, quando é preciso estar de prontidão para receber a bola a qualquer momento, acompanhando sempre os movimentos da jogadora que está de sua posse.

Somado aos movimentos até aqui citados (sejam eles com ou sem bola), há ainda as formações, que são disputas de bola com dinâmicas muito específicas. Durante as observações, notou-se que a realização do scrum, do ruck e do lineout exige muita coesão e sincronia por parte das jogadoras. Isso ocorre também durante o treino de jogadas ensaiadas, em que todas precisam saber exatamente como a jogada funciona, quais os movimentos a serem realizados, de quem se receberá a bola e para quem esta será passada, se for o caso. Pode-se comparar essa movimentação tática a expressões coreográficas em que cada movimento deve ser bem ensaiado, em que a ação de cada participante precisa estar concatenada com a do outro. Algo que também ocorre no caso das formações, que são uma combinação de obrigatoriedade do jogo (como o scrum e o lineout, por exemplo) com a tática da equipe (já que a forma de fazer o levantamento na cobrança de lineout, por exemplo, é uma escolha do time, que depende das pretensões táticas do momento).

Pensou-se coreografia aqui em um sentido tradicional, como uma peça caracterizada pela "combinação de passos do vocabulário" da dança em questão (balé, dança moderna, de salão, enfim), "em variações que [acompanham] a música” (SILVA, 2005, p. 94). A manipulação dos gestos e dos movimentos, a utilização do espaço e a construção estrutural das danças em grupo parecem ser os elementos principais da composição coreográfica (SILVA, 2005) que mais se aproximam do rúgbi. As jogadas táticas, bem como as formações que compõem a dinâmica do jogo, realizam-se por meio da utilização dos gestos técnicos da modalidade, da exploração do campo de jogo, da sincronia e da coesão das jogadoras para concretização das jogadas. Treinar e ensaiar encontram-se como sinônimos. Ambos buscam a incorporação dos movimentos e ações individuais que, combinados, geram uma performance.

Diferentemente do caráter fechado que as composições coreográficas tradicionais, como o balé, por exemplo, têm (é só lembrar dos incontáveis espetáculos milimetricamente produzidos e documentados, 
possibilitando sua repetida montagem por diferentes companhias de dança do mundo inteiro, como Giselle, $O$ lago dos cisnes e O quebra-nozes etc.), no esporte nunca se pode saber de antemão se aquilo que foi ensaiado se realizará. Isso porque o jogo esportivo depende do outro e da imprevisibilidade que este pode proporcionar no decorrer da partida, impedindo que jogadas sejam feitas e, ao mesmo tempo, possibilitando que outras se apresentem.

Nesse emaranhado de coreografia e esporte, é preciso destacar um elemento comum a todos: o ritmo. No caso do rúgbi, em especial no sevens, o ritmo tende a ser, como já visto, dinâmico e veloz, devido ao tempo reduzido de jogo e também à quantidade de jogadores em campo, o que faz com que haja menos contato físico. É preciso então treinar a agilidade das jogadoras, com corridas e passes mudando de direção, imprimindo ritmo acelerado aos exercícios, assim como acontece no jogo. Verificase aqui que há uma correlação entre ritmo e tempo que parece ser mediada pelo timing das jogadoras, que devem ser capazes de agir de modo certo no momento correto: devem estar atentas à movimentação da defesa, bem como do ataque, permanecer em sincronia com as jogadas ensaiadas e responder prontamente quando da solicitação para receber a bola ou mesmo realizar um passe.

Segundo Gumbrecht (2007), o timing é um fenômeno temporal essencial para todos os esportes, sendo "a fusão perfeita entre a percepção do espaço e o início do movimento (...) é a capacidade intuitiva de colocar o corpo num espaço específico no momento exato em que ele precisa estar lá" (p. 140). Mas isso não significa que o timing não é algo apreendido. Pelo contrário, muito é preciso treinar para incorporar o tempo certo das jogadas e da movimentação. Novamente, volta-se ao senso prático no esporte, nos termos expostos por Gebauer (1995): quanto menos as jogadoras refletem sobre o que precisam fazer, mais eficiente se torna seu jogo. Sendo assim, treino é fundamental, não apenas dos gestos técnicos, mas também da utilização do espaço, da movimentação com e sem bola, da relação com as companheiras de equipe, como se constatou no trabalho de campo. Tudo deve estar em sincronia para garantir a vitória (ou ao menos um jogo o mais eficaz possível): o condicionamento físico, a técnica e o esquema tático. Destes depende o bom ritmo da partida, característica que, associada à harmonia, garante, na análise de Huizinga (2007), o caráter estético do jogo, que guarda em si a tendência de ser belo, "fascinante" e "cativante".

\section{Alguns APONTAMENTOS PARA SEGUIR PENSANDO}

Ao se propor pensar as dimensões estéticas do esporte com o olhar voltado para os seus praticantes, trazendo para o centro da análise o cotidiano dos atletas, bem como suas vozes, depara-se com um emaranhado de elementos que ajudam a compor tal quadro.

Uma primeira questão a ser considerada é o lugar de protagonismo do corpo e o papel que este desempenha na concretização do esporte. É este, ao mesmo tempo, limite e potência, natureza a ser milimetricamente dominada que leva à máxima performance, bem como à perfeição da forma. No caso pesquisado, o corpo se deixa ver como matéria necessária para a construção da obra esportiva, como pura materialidade a ser usada pelos princípios do treinamento. Sua transformação resulta de um processo doloroso, intenso e exaustivo, cheio de abdicações e de excessos. Assim como ocorre na arte, também no esporte é preciso violentar a matéria para se poder criar formas, a partir da geração do material que, segundo a análise aqui realizada, constitui-se pelos movimentos esportivos.

Assim, os gestos técnicos, como material disponível para a obra esportiva, configuram-se como o vocabulário específico da linguagem do esporte. No rúgbi, há uma riqueza nesse vocabulário, nas várias possibilidades de movimentação: pode-se correr segurando a bola, chutá-la, mas também realizar passes com as mãos, ir ao chão com um adversário ou às alturas durante um levantamento, quando da disputa da ovalada. Enfim, inúmeras combinações são possíveis de serem realizadas durante uma partida. E estas somente são alcançadas por meio da apreensão técnica de tais movimentos, o que remete, novamente, ao processo de treinamento.

Se a obra artística não é resultado de um gênio, mas do engenho humano, de muito trabalho e desenvolvimento técnico, algo similar ocorre com o esporte, em que a obra esportiva se constrói por meio do exaustivo treinamento que tem no corpo sua centralidade. Imaginação e trabalho que humanizam a natureza tornada força expressiva. Não se quer dizer com isso que o esporte é o mesmo que a arte, mas sim que neste há potência expressiva e que se pode fruí-lo esteticamente, seja ao assisti-lo, seja ao praticá-lo, conferindo-lhe novos sentidos que não estejam restritos apenas ao código vitória-derrota, ao considerá-lo em seu potencial de construir formas.

Ao se trabalhar com os conceitos de matéria e material, mas também de forma, inspira-se, como antes assinalado, em elementos que constituem a obra de arte, segundo Adorno e toda uma tradição clássica, a saber: forma, material e conteúdo. O primeiro concerne ao conjunto de todos os elementos artísticos da obra e é o que lhe confere especificidade, ou seja, seu estatuto de arte. O segundo é a conjunção da matéria e do espírito objetivado, gerando aquilo com que os artistas trabalham. E, por fim, o conteúdo é "aquilo que é alcançado na obra de arte a partir de sua estruturação formal [sendo] um sedimento histórico da vivência coletiva" (FREITAS, 2003, p. 43). 
Observe-se que neste texto a ênfase recai sobre matéria, e não sobre conteúdo, porque a primeira tem protagonismo na conformação da obra esportiva, já que o corpo, como instrumento técnico por excelência, encarna em si a ancestral cisão entre natureza e cultura, sujeito e objeto, sendo ao mesmo tempo pura materialidade operacionalizável (VAZ, 2004b) e potência expressiva. No que diz respeito ao conteúdo, não se pode deixar de dizer que este faz residir uma distinção fundamental entre esporte e arte. Para entendê-la, faz-se necessário partir daquilo que faz ambos encontrarem-se, a saber: seu caráter de jogo.

Como assinala Adorno (1997a), em Teoria estética, "Em seu fazer todo jogo faz renunciar, no plano de seu conteúdo, à praxis, embora em sua forma, vincule-se inteiramente a ela" (p. 371). Ou seja, o jogo afasta-se da práxis no que diz respeito ao seu conteúdo, pois não é voltado a fins, mas desta se aproxima em relação à forma, já que todo jogo configura-se como representação da práxis social, mimesis, como aponta Gebauer (1995). Tal representação consiste, justamente, no momento de repetição (Wiederholungsmoment) presente em toda forma de jogo (Spielform), sendo que a própria repetição é a imagem espelhada (Nachbild) do trabalho, quer dizer, da práxis que, na sociedade capitalista, é sempre dominadora.

Se toda forma de jogo é repetição (ADORNO, 1997a, 369) e, se o esporte é a "forma não artística dominante do jogo" (ADORNO, 1997a, p. 371), no contemporâneo, tal repetição se faz presente também na forma esportiva. Entretanto, diferentemente do que ocorre no jogo presente na arte ou mesmo, pelo menos até certo ponto, nas brincadeiras infantis, no esporte a repetição consiste na reprodução da lógica do trabalho, aproximando ainda mais os homens da práxis sem que eles se apercebam (ADORNO, 1997a; 1997b). Para Adorno (1997a), portanto, a perspectiva posta por Huizinga, mencionada na introdução deste texto, estaria correta e simultaneamente incorreta, na medida em que ele toma o conceito de jogo, como origem da cultura, de forma abstrata, faltando-lhe considerar a objetividade social.

Assim, o esporte seria, objetivamente, uma espécie de degradação do jogo, ao não se esvaziar de uma orientação a fins (Zweck). Por isso, já adiantara Adorno, em 1938, ao tratar da música fetichista e seu processo de esportivização:

Não por acaso, o esporte burguês quer estar tão marcadamente separado do jogo. Seu rigor brutal significa que, em lugar de manter a confiança no sonho da liberdade por meio do distanciamento quanto aos fins, acaba-se por colocar o jogo, como obrigação, sob o jugo das finalidades úteis, por meio do qual se extingue qualquer vestígio de liberdade (1997c, p. 47).

\section{REFERÊNCIAS}

ADORNO, Theodor Wiesegrund. Ästhetische Theorie. Frankfurt am Main: Suhrkamp, 1997a. (Gesammelte Schriften - Adorno, 7).

Veblens Angriff auf die Kultur. Frankfurt am Main: Suhrkamp, 1997b. (Gesammelte Schriften -Adorno, 10. Tomo 1).

Über Fetischcharakter in der Musik und die Regression des Hörens. Frankfurt am Main: Suhrkamp, 1997c. (Gesammelte Schriften - Adorno, 14).

BOURDIEU, Pierre. El conocimiento por cuerpos. In: Meditaciones Pascalianas. Barcelona: Anagrama, 1999. p. $169-214$.

CLAUSSEN, Detlev. Sobre a estupidez no futebol. Análise Social, Lisboa, v. XLI, n. 179, p. 583-592, 2o trimestre 2006.

ELIAS, Norbert; DUNNING, Eric. A busca da excitação. Lisboa: Difel, 1992.

FREITAS, Verlaine. Adorno e a arte contemporânea. Rio de Janeiro: Jorge Zahar, 2003.

GAGNEBIN, Jean Marie. Do conceito de mimesis no pensamento de Adorno e Benjamin. In: Sete aulas sobre linguagem, memória e história. Rio de Janeiro: Imago, 2005. p. 79-104.

GEBAUER, Gunter. Ästhetische Erfahrung der Praxis: das Mimetische im Sport. In: KÖNIG, E.; LUTZ, R. (Org.). Bewegungskulturen: Ansätze zu einer kritischen Anthropologie des Körpers. SanktAugustin: Academia Verlag, 1995. p. 189-198.

GEBAUER, Gunter; WULF, Christoph. Mimese na cultura: agir social, rituais e jogos, produções estéticas. São Paulo: Annablume, 2004.

GONÇALVES, Michelle Carreirão; VAZ, Alexandre Fernandez. Mimesis e estética da presença: o esporte como artefato estético, a partir de Theodor W. Adorno e Hans Ulrich Gumbrecht. Revista Portuguesa de Ciências do Desporto, Porto, v. 12 (supl.), p. 9-99, 2012.

GONÇALVES, Michelle Carreirão; TURELLI, Fabiana Cristina; VAZ, Alexandre Fernandez. Corpos, dores, subjetivações: notas de pesquisa no esporte, na luta, no balé. Movimento, Porto Alegre, v. 18, n. 3, p. 141-158, jul.-set. 2012.

GUMBRECHT, Hans Ulrich. A forma da violência: em louvor da beleza atlética. Folha de São Paulo, mar. 2001. Caderno "Mais!", p. 4-7. Letras, 2007.

Elogio da beleza atlética. São Paulo: Companhia das

HORKHEMER; Max; ADORNO, Theodor Wiesegrund. Dialektik der Aufklärung: Philosophische Fragmente. Frankfurt am Main: Suhrkamp, 1997. (Gesammelte Schriften - Adorno, 3).

HUIZINGA, Johan. Homo ludens: o jogo como elemento da cultura. São Paulo: Perspectiva, 2007.

PASOLINI, Pier Paolo. O gol fatal. Folha de São Paulo, mar. 2005. Caderno “Mais!", p. 4-5.

SABINO, Cesar. Musculação: expansão e manutenção da masculinidade. In: GOLDENBERG, M. (Org.). Os novos desejos: das academias de musculação às agências de encontros. Rio de Janeiro: Record, 2000, p. 61-103. 
SILVA, Eliana Rodrigues. Dança e pós-modernidade. Salvador: Edufba, 2005.

VAZ, Alexandre Fernandez. Sport und Sportkritik in der Kultur- und Zivilisationsprozess: Analysen nach Adorno und Horkheimer, Elias und DaMatta. Frankfurt am Main: Afra, 2004a. 161 p.

Corpo e indústria cultural: notas para pensar a educação na sociedade contemporânea. In: ZUIN, A. S.; PUCCI, B.; DE OLIVEIRA, N. R. (Org.). Ensaios frankfurtianos. São Paulo: Cortez, 2004b. p. 117-135.
WACQUANT, Löic. Corpo e alma: notas etnográficas de um aprendiz de boxe. Rio de Janeiro: Relume Dumará, 2002.

WELSCH, Wolfgang. Esporte - visto esteticamente e mesmo como arte? In: ROSENFIELD, D. L. (Org.). Ética e estética Rio de Janeiro: Jorge Zahar Ed., 2001. p. 142-165.

WISNIK, José Miguel. Veneno remédio: o futebol e o Brasil. São Paulo: Companhia das Letras, 2008.

Recebido em 13-12-2015.

Aprovado em 04-12-2016. 